\title{
Oralidade formal e argumentação: a importancia de se trabalhar com o gênero debate regrado na educação básica
}

\author{
Formal orality and argumentation: the importance of working \\ with genre regulated debate in basic education \\ Sirley Ribeiro Siqueira de Oliveira \\ Colégio Pedro II \\ DOI: https://doi.org/10.5902/2176148538805
}

Resumo: "Por que devemos fazer da oralidade um objeto de ensino?" e "Por que o gênero textual debate regrado pode se tornar um importante instrumento para a aquisição de usos formais da fala em público?" Nesse artigo, buscamos responder a essas perguntas, subsidiados por um aporte teórico que considera a língua como interação. Por isso, somamos nossas ideias às de outros pesquisadores que defendem que usos mais formais da língua falada demandam um ensino planejado, sistemático e contínuo. Além disso, apresentamos uma proposta de prática de ensino desenvolvida com alunos do Ensino Médio, que alia oralidade formal e argumentação.

Palavras-chave: Oralidade formal. Argumentação. Ensino

\begin{abstract}
Why should we make orality an object of teaching?" and"Why the genre regulated debate can become an important tool for the acquisition of formal uses of public speaking?" In this article, we aim to answer these questions and our theoretical framework is anchored in the conception of language as interaction. Therefore, we add our ideas to those of other researchers who argue that more formal uses of the spoken language demand a planned, systematic and continuous teaching. In addition, we present a proposal of teaching practice developed with students of High School, which congregate formal orality and argumentation.
\end{abstract}

Keywords: Formal orality. Argumentation. Teaching 


\section{Sirley Ribeiro}

Siqueira de

Oliveira

\section{Introdução}

Desde a década de 1980, muitas pesquisas já foram publicadas em torno do ensino de Língua Portuguesa, com destaque para a necessidade de avançarmos, a fim de que o trabalho, sobretudo na Educação Básica, não se restrinja ao texto escrito, conforme se pode observar em Marcuschi (1986), Koch (1996), Castilho \& Basílio (1996) e Castilho (1998). Como resultado de tamanha produtividade acerca do tema, os Parâmetros Curriculares Nacionais (1997) (doravante, PCN) incorporaram e trouxeram ainda maior legitimidade para o assunto. De acordo com o documento: acesso a usos da linguagem mais formalizados e convencionais, que exijam controle mais consciente e voluntário da enunciação, tendo em vista a importância que o domínio da palavra pública tem no exercício da cidadania. Ensinar língua oral não significa trabalhar a capacidade de falar em geral. Significa desenvolver o domínio dos gêneros que apoiam a aprendizagem escolar de Língua Portuguesa e de outras áreas (exposição, relatório de experiência, entrevista, debate etc.) e, também, os gêneros da vida pública no sentido mais amplo do termo (debate, teatro, palestra, entrevista etc.). Já que os alunos têm menos acesso a esses gêneros nos usos espontâneos da linguagem oral, é fundamental desenvolver, na escola, uma série de atividades de escuta orientada, que possibilitem a eles construir, progressivamente, modelos apropriados ao uso do oral nas circunstâncias previstas. (BRASIL, 1997, p.67).

Duas décadas após a publicação dos PCN, o tema continua extremamente relevante, uma vez que não é uma tarefa fácil conciliar o ensino de leitura e produção escrita ao trabalho com escuta e produção de textos orais, especialmente aqueles que requerem um grau maior de formalidade. Em um esforço para atualização e manutenção dessa discussão, foi lançada, em 2017, a Base Nacional Curricular Comum (BNCC), na qual encontramos explícitos os seguintes eixos organizadores para o ensino de Língua Portuguesa: oralidade, leitura, escrita, conhecimentos linguísticos e gramaticais e educação literária (BRASIL, 2017, p. 6465). Entendemos que, de fato, trabalhar todos esses eixos é um desafio que precisa ser enfrentado e acreditamos que, por meio de referenciais 
teórico-metodológicos consistentes e práticas de ensino, voltadas tanto para a modalidade escrita quanto para a modalidade oral, seja possível contribuirmos para que a formação do educando na Educação Básica seja cada vez mais ampla.

KOCH (2002, p. 17) destaca que numa concepção interacional da língua, na qual os sujeitos são vistos como atores/ construtores sociais, "o texto passa a ser considerado o próprio lugar de interação e os interlocutores, como sujeitos ativos que - dialogicamente - nele constroem e são construídos". Ancorar nossas práticas diárias de sala de aula nessa concepção de texto e de sujeitos é um importante passo para refletirmos sobre o que consideramos prioridade nas aulas de Língua Portuguesa, tendo em mente nosso compromisso como educadores, os quais desejam contribuir para a formação de cidadãos pensantes e que não se

Oralidade formal e argumentação calam frente a injustiças. Portanto, de modo a reiterar a importância de tal temática, este artigo tem como objetivo contribuir para a expansão das discussões que envolvem o ensino da oralidade no âmbito escolar (RAMOS, 2002; GOMES-SANTOS, 2009; LEAL; GOIS, 2012; NONATO, 2018), especialmente por meio da apresentação de uma prática de ensino baseada no trabalho com o gênero debate regrado.

No decorrer do texto, procuraremos responder a duas perguntas "Por que devemos fazer da oralidade um objeto de ensino?" e "Por que o gênero textual debate regrado pode se tornar um importante instrumento para a aquisição de usos formais da fala em público?". Além disso, também discorreremos acerca de um projeto de iniciação científica júnior denominado Argumentação e Oralidade, desenvolvido com alunos do Ensino Médio do Colégio Pedro II, uma escola pública federal localizada no município do Rio de Janeiro, cujo principal eixo de ação foi a criação de uma Sociedade de Debates, sobre a qual discorreremos adiante.

\section{Por que devemos fazer da oralidade um objeto de ensino?}

Já há bastante tempo foi abandonada a ideia dicotômica de que a fala e a escrita se opõem. Isso se deu porque o avanço dos estudos linguísticos mostrou que caracterizar a escrita como planejada, elaborada e a fala como não planejada ou pouco elaborada, por exemplo, era uma generalização pouco aplicável frente à variedade de gêneros textuais que circulam em nossa sociedade. De acordo com Koch; Elias, 
Sirley Ribeiro

Siqueira de

Oliveira

446

(...) tais características foram sempre estabelecidas tendo por parâmetro o ideal de escrita (isto é, costumava-se olhar a língua falada através das lentes de uma gramática projetada para a escrita), o que levou a uma visão preconceituosa da fala (descontínua, pouco organizada, rudimentar, sem qualquer planejamento), que chegou a ser comparada à linguagem rústica das sociedades primitivas ou à das crianças em fase de aquisição de linguagem. (KOCH; ELIAS, 2012, p.16)

A divulgação, no meio acadêmico, de trabalhos como os de Marcuschi (2001) tem colaborado para consolidar o entendimento de que a fala e a escrita apresentam diferenças que se manifestam em um continuum tipológico no qual podem ser observados dois polos. Próximos a um desses polos, estão os gêneros textuais orais, que requerem menos formalidade, como conversações espontâneas entre amigos; no outro extremo, se encontram os gêneros textuais escritos mais formais, como textos acadêmicos.

Ainda dentro desse continuum, há gêneros da modalidade escrita bastante informais, como conversas escritas de WhatsApp e bilhetes, que se aproximam da fala não planejada, situando-se, portanto, próximos a esse polo. Por outro lado, há também vários outros textos orais que se assemelham à escrita formal, como conferências e entrevistas profissionais, que beiram o polo oposto. Está claro, por conseguinte, que a existência de tais gêneros ou ainda de outros mais intermediários justifica o abandono da percepção dicotômica que opunha fala e escrita.

Justamente por haver em nossa sociedade tantos gêneros orais e por existirem tantas ocasiões, em que se faz necessário o uso da fala de maneira mais formal, que exigem, portanto, planejamento, é que se torna relevante fazer da oralidade um objeto de ensino. Acreditamos que a escola precisa tomar para si a tarefa de levar os alunos a irem além do domínio do oral cotidiano e buscar meios para que o ensino da oralidade formal tenha efetivamente seu espaço no ambiente escolar. É preciso, por conseguinte, empreender atividades que mostrem aos alunos que há gêneros da oralidade que demandam controle consciente e voluntário do próprio comportamento e que exigem preparação. Esse mesmo entendimento é compartilhado por Costa-Maciel e Bilro, quando afirmam que: 
Focar o ensino da oralidade no estudo desses gêneros [formais] possibilita aos indivíduos desenvolver competências que, em geral, não são apreendidas no cotidiano, por não fazerem parte das instâncias privadas de produção e por demandarem um maior grau de planejamento no uso da fala pública. (COSTA-MACIEL \& BILRO, 2018, p.2)

\section{Por que o gênero textual debate regrado pode se tornar um importante instrumento para a aquisição de usos formais da fala em público?}

Em nossa sociedade, circulam muitos gêneros orais que podem ser escolhidos para se trabalhar a oralidade formal, como, por exemplo, o seminário, a entrevista, o júri simulado; entretanto, o caráter dialógico ${ }^{1}$, inerente ao debate, é um aspecto de muita relevância a ser considerado. Por ser um gênero de produção on-line, exige, dos debatedores, dentre outras habilidades, tanto a capacidade de produzir bons argumentos quanto a competência para ouvir os argumentos contrários aos seus, com a expectativa de desconstruí-los. Dessa forma, o trabalho recorrente com o gênero debate regrado mostra-se capaz de exercitar a fala formal em público, ao mesmo tempo em que amplia o escopo da argumentação, muitas vezes, restrito ao texto escrito em contextos escolares.

A obra de Perelman e Olbrechts-Tyteca (1958) é um marco para a ressignificação do conceito de argumentação. Posteriormente a ela, diversos outros estudos surgiram dando novo fôlego à área e impulsionando uma série de pesquisas em diferentes áreas. Dentro da Análise do Discurso, por exemplo, tem sido um ponto pacífico que, entre os gêneros textuais do argumentar, há aqueles com menor intenção de agir sobre o outro para o convencimento; e há aqueles nos quais há um nítido interesse em persuadir o interlocutor de modo a fazer com que adote determinada postura ou aceite determinado ponto de vista.

Esse entendimento de que há diferentes graus de argumentatividade reforça a relevância dos estudos sobre a argumentação. Além disso, reitera a importância de tratarmos da argumentação em toda a Educação Básica, uma vez que se tem como ideal de formação aquela que se pauta no desejo de contribuir para a formação de sujeitos capa-

1 O caráter "dialógico", no sentido bakhtiniano, seria inerente a qualquer texto. No sentido aqui utilizado, está mais relacionado ao diálogo em si, à alternância de turnos imediata entre os interlocutores, própria da natureza do gênero oral debate. 
Sirley Ribeiro

Siqueira de

Oliveira

zes de entender as teses subjacentes aos discursos alheios e de veicular com clareza as suas próprias ideias e defendê-las. Seguindo essa linha de raciocínio, como já dissemos, o trabalho com o gênero debate regrado se justifica ainda mais, por ser um gênero oral que se caracteriza pelo alto nível de argumentatividade que lhe é intrínseco, ou seja, faz parte da própria natureza do debate a mobilização de diversos argumentos para atuar na persuasão do interlocutor.

Cabe frisar também que, em um contexto de escola pública, na qual, muitas vezes, os estudantes são oriundos de camadas pouco letradas, o compromisso com o ensino da argumentação precisa ser ainda maior. Isso se faz necessário, especialmente, se almejamos contribuir para a formação de uma sociedade cada vez mais democrática, na qual todos os cidadãos possam compreender discursos autoritários e/ou eivados de preconceito. Ademais, acreditamos que possibilitar a apropriação de estratégias argumentativas é uma maneira de empoderar cidadãos a fim de que possam reivindicar seus direitos, garantidos, aliás, pela Constituição Federal. Com o intuito, portanto, de qualificar os alunos por meio de práticas linguísticas significativas - um dos caminhos para a desmarginalização social, conforme nos aponta Negreiros e Vilas Boas (2017, p. 116), elaboramos um projeto de iniciação científica, denominado Argumentação e oralidade, responsável pela implementação de uma Sociedade de Debates no Colégio Pedro II, sobre o qual discorreremos na próxima seção.

\section{Por ações que deem voz aos alunos}

O Ensino Médio é a última etapa da Educação Básica e um dos seus objetivos é preparar os jovens para o mundo do trabalho e também para a ascensão a outros patamares do sistema de ensino, nos quais os usos formais da modalidade oral são uma constante. Diante desse desafio, lançado a toda comunidade escolar, escolhemos oferecer uma contribuição por meio do Argumentação e oralidade. Tal projeto busca coadunar-se com o que está exposto em Dolz, Noverraz e Schneuwly (2004, p. 82), os quais definem sequência didática " como um conjunto de atividades escolares organizadas, de maneira sistemática em torno de um gênero textual oral ou escrito". Assim, com a finalidade de ajudar os alunos a dominarem melhor o gênero debate regrado, elaboramos a seguinte sequência didática, a qual foi desenvolvida com os alunos antes do primeiro debate ser realizado: 


\section{Quadro 1 : Sequência didática preparatória para o debate regrado}

\begin{tabular}{|c|c|c|c|c|}
\hline OFICINAS & OBJETIVOS & ATIVIDADES & MATERIAL & DURAÇÃo \\
\hline $\begin{array}{l}\text { Apresentação } \\
\text { de um debate }\end{array}$ & $\begin{array}{l}\text { 1. Despertar o interesse pelo } \\
\text { gênero debate regrado. } \\
\text { 2. Levar os alunos a ouvir } \\
\text { com atenção os argumen- } \\
\text { tos expostos por cada } \\
\text { debatedor. } \\
\text { 3. Demonstrar como se dá } \\
\text { a contra-argumentação na } \\
\text { modalidade oral. }\end{array}$ & $\begin{array}{l}\text { Apresentação de um } \\
\text { debate promovido } \\
\text { por universitários } \\
\text { pertencentes a outras } \\
\text { Sociedades de Debates } \\
\text { do Rio de Janeiro. }\end{array}$ & $\begin{array}{l}\text { 1.Pilot e quadro } \\
\text { (para anotar o } \\
\text { tema). } \\
\text { 2.Mesas e } \\
\text { cadeiras para os } \\
\text { espectadores. } \\
\text { 3.Sineta para } \\
\text { controlar o } \\
\text { tempo de cada } \\
\text { debatedor. }\end{array}$ & $1 \mathrm{~h} 20 \mathrm{~min}$. \\
\hline $\begin{array}{l}\text { Módulo 1: } \\
\text { Regras de } \\
\text { cortesia e o } \\
\text { gênero de- } \\
\text { bate regrado } \\
\text { (parte 1) }\end{array}$ & $\begin{array}{l}\text { 1.Destacar a importância de } \\
\text { se manter a cortesia, com a } \\
\text { adoção de palavras e expres- } \\
\text { sões que indiquem respeito } \\
\text { aos demais debatedores. } \\
\text { 2.Apresentar em detalhes } \\
\text { os papéis dos primeiros } \\
\text { quatro debatedores. }\end{array}$ & $\begin{array}{l}\text { Exposição oral do } \\
\text { professor acerca do } \\
\text { gênero debate regra- } \\
\text { do, suas regras de } \\
\text { cortesia e os papéis } \\
\text { pré-definidos para } \\
\text { os quatro primeiros } \\
\text { debatedores. }\end{array}$ & $\begin{array}{l}\text { 1.Pilot e quadro. } \\
\text { 2.Documento em } \\
\text { vídeo contendo } \\
\text { a primeira parte } \\
\text { de um debate } \\
\text { regrado }\end{array}$ & $45 \mathrm{~min}$. \\
\hline $\begin{array}{l}\text { Módulo 2: } \\
\text { Regras de } \\
\text { cortesia e o } \\
\text { gênero de- } \\
\text { bate regrado } \\
\text { (parte 2) }\end{array}$ & $\begin{array}{l}\text { 1.Levá-los a compreen- } \\
\text { der a importância de se } \\
\text { respeitar a opinião alheia } \\
\text { e de saber ouvi-la com } \\
\text { respeito e tolerância. } \\
\text { 2. Apresentar em detalhes } \\
\text { os papéis dos quatro } \\
\text { últimos debatedores. }\end{array}$ & $\begin{array}{l}\text { Reiteração oral do } \\
\text { professor acerca da } \\
\text { importância de se } \\
\text { criar um ambiente } \\
\text { de cordialidade e } \\
\text { empatia; os papéis } \\
\text { dos quatro últimos } \\
\text { debatedores. }\end{array}$ & $\begin{array}{l}\text { 1.Pilot e quadro. } \\
\text { 2.Documento em } \\
\text { vídeo contendo } \\
\text { a segunda parte } \\
\text { de um debate } \\
\text { regrado. }\end{array}$ & $45 \mathrm{~min}$. \\
\hline $\begin{array}{l}\text { Módulo } 3^{3} \text { : } \\
\text { A fala em } \\
\text { público }\end{array}$ & $\begin{array}{l}\text { 1. Fazer com que os que têm } \\
\text { receio de falar em público } \\
\text { possam vencer a timidez e } \\
\text { expressar a sua opinião so- } \\
\text { bre um tema da atualidade. }\end{array}$ & $\begin{array}{l}\text { Cada aluno tem a } \\
\text { oportunidade de falar } \\
\text { por até dois minutos. }\end{array}$ & $\begin{array}{l}\text { Mesa e cadeiras } \\
\text { em círculo }\end{array}$ & $1 \mathrm{~h}$ \\
\hline $\begin{array}{l}\text { Módulo 4: a } \\
\text { prepara- } \\
\text { ção para o } \\
\text { debate }\end{array}$ & $\begin{array}{l}\text { 1.Deliberar com os alunos } \\
\text { o tema do debate. } \\
\text { 2.Esclarecer a importância } \\
\text { do estudo e do planeja- } \\
\text { mento do discurso a ser } \\
\text { proferido no debate. }\end{array}$ & $\begin{array}{l}\text { 1. Levantamento de } \\
\text { temas do interesse } \\
\text { dos alunos e relevan- } \\
\text { tes para a sociedade. } \\
\text { De preferência, esses } \\
\text { assuntos devem estar } \\
\text { ligados aos diversos } \\
\text { campos de saberes } \\
\text { a que os alunos têm } \\
\text { acesso na escola. } \\
\text { 2. Exposição oral do } \\
\text { professor acerca da re- } \\
\text { levância de se preparar } \\
\text { para o debate, por meio } \\
\text { da pesquisa, atentando- } \\
\text {-se para o fato de que } \\
\text { é necessário estudar } \\
\text { argumentos favoráveis } \\
\text { e contrários ao tema. }\end{array}$ & $\begin{array}{l}\text { Pilot e quadro } \\
\text { para anotar os } \\
\text { temas sugeridos } \\
\text { e promover a } \\
\text { escolha dos mais } \\
\text { adequados. }\end{array}$ & $30 \min$. \\
\hline
\end{tabular}

Oralidade

formale

argumentação

2 Como o colégio em que está sendo desenvolvido o projeto fica na capital do Rio de Janeiro, torna-se mais fácil entrar em contato com universitários para apresentação ao vivo do debate. Outros professores, entretanto, sem essa possibilidade, podem acessar o link <http://ibdebates.org/site/videos> no qual encontrarão muitos vídeos de debates de altíssima qualidade, promovidos por universitários de todo o Brasil.

3 Consideramos bastante produtiva a atividade de fala em público antes da realização do debate regrado. É uma excelente oportunidade para os alunos perderem a inibição e se acostumarem à fala que requer maior planejamento. 
A elaboração da sequência didática acima foi importante para que pudéssemos ter mais clareza quanto ao passo a passo necessário a fim de que os alunos conhecessem o gênero escolhido como instrumento para aquisição e/ou aperfeiçoamento da oralidade formal. Concordamos com Carvalho e Ferrarezi Jr. (2018, p. 31) ao afirmarem que o trabalho com a oralidade deva ocorrer em sala de aula, como um conteúdo programático. Entretanto, a definição do currículo e da carga horária de cada disciplina ainda não é feita isolada-

Sirley Ribeiro

Siqueira de

Oliveira

450 mente por cada professor. Infelizmente, as escolas ainda possuem programas que privilegiam excessivamente o ensino de gramática, quando o tempo gasto nessa tarefa poderia estar sendo investido na ampliação das competências de ler, escrever, ouvir e falar, conforme está exposto nos PCN (Brasil, 1997, p.23). Além disso, nem todos os professores compartilham do entendimento de que o ensino dessas competências é de responsabilidade de todos os docentes e não apenas do professor de Português, conforme prevê os PCN (Brasil, 1997, p. 50). Assim, dentro da realidade da nossa escola, para que fosse possível seguir a sequência didática que elaboramos, de maneira sistemática e contínua, propusemos a iniciação científica, com o intuito de que o trabalho com a oralidade não se restringisse a dias isolados ao longo do ano.

O projeto, atualmente, conta com quatro alunos bolsistas e três alunos voluntários. Esses alunos, ao lado da professora responsável, atuam diretamente na escolha dos temas, na divulgação do calendário de debates para os demais alunos da escola e no convite a palestrantes externos (em geral, universitários experientes também envolvidos com o movimento de debates). A participação como debatedor ou como ouvinte é voluntária e aberta a qualquer aluno do Ensino Médio. De modo a atender os dois turnos em que a escola funciona, sem prejudicar as aulas regulares de outras disciplinas, foi escolhido o horário de $12 \mathrm{~h}$ às 13h para a realização dos debates ou para a ministração de módulos preparatórios.

Uma Sociedade de Debates consiste em um grupo organizado de alunos debatedores e juízes e, geralmente, segue o padrão do Parlamento Britânico (motivo pelo qual os debatedores são chamados de deputados ao longo do debate). Em tal modelo, há quatro duplas de debatedores que discutem a moção (recorte mais específico do tema estabelecido) dada no dia do debate. Também no dia do evento, os deba- 
tedores descobrem se terão que argumentar favoravelmente à moção ou se deverão apresentar argumentos contrários a ela, de modo que duas duplas fiquem, portanto, a favor e duas duplas sejam contrárias, formando-se duas bancadas de duas duplas cada. O primeiro debatedor, a proferir o seu discurso, pertence à bancada de defesa e o segundo, à bancada de oposição. Cada debatedor tem até sete minutos para apresentar seus argumentos.

Seguindo esse padrão, também há alguns papéis pré-definidos a serem cumpridos pelos debatedores: o primeiro debatedor, da bancada de defesa, precisa fazer a definição da moção, ou melhor, escolher, dentre as palavras que compõem a moção, algumas delas para defini-las de modo a manter o recorte dado na moção e favorecer a sua bancada. O último debatedor de cada bancada tem a função de

Oralidade formal e argumentação resumir os argumentos apresentados por sua bancada com o intuito de reiterar a relevância de tais argumentos e justificar por que os argumentos escolhidos foram os mais convincentes para a defesa de suas ideias.

A avaliação é feita por dois ou três avaliadores (em geral, a professora e dois alunos mais experientes) e julga a apresentação de argumentos acompanhados de referências, a oratória, a linha de raciocínio, a capacidade de responder as perguntas feitas e de refutar os argumentos da bancada oposta e, finalmente, de seguir as regras estabelecidas pelo modelo. Ao final do debate, é declarado qual foi o melhor debatedor individual e qual foi a melhor dupla. Os avaliadores também precisam dar a todos os debatedores um "feedback" acerca do seu desempenho individual, baseando-se nos critérios anteriormente descritos. Além disso, é encaminhado, por Whatsapp, o áudio do debate para que cada debatedor possa ouvir o seu próprio discurso e o dos colegas e, assim, melhorar cada vez mais as competências de ouvir e falar.

Ao observarmos os $\mathrm{PCN}$, percebemos que a realização constante de debates contribui de maneira significativa para o cumprimento dos propósitos estabelecidos no documento em relação ao ensino da oralidade formal. A seguir, apresentamos uma figura na qual são expostos os objetivos traçados pelo documento para o treinamento da fala em público e como as ações desenvolvidas ao longo dos debates são capazes de atingi-los. 


\section{Sirley Ribeiro \\ Siqueira de \\ Oliveira}

Segundo os PCN (BRASIL,1997, p. 51), espera-se que o aluno: (grifos nossos)

planeje a fala pública usando a linguagem escrita em função das exigências da situação e dos objetivos estabelecidos;

considere os papéis assumidos pelos participantes, ajustando o texto à variedade linguística adequada;

saiba utilizar e valorizar o repertório linguístico de sua comunidade na produção de textos;

monitore seu desempenho oral, levando em conta a intenção comunicativa e a reação dos interlocutores e reformulando o planejamento prévio, quando necessário;

considere possíveis efeitos de sentido produzidos pela utilização de elementos não-verbais

$\rightarrow \rightarrow$\begin{tabular}{l}
$\begin{array}{l}\text { Ações inerentes ao gênero debate } \\
\text { regrado }\end{array}$ \\
\hline $\begin{array}{l}\text { Os alunos são orientados a pesquisa- } \\
\text { rem sobre o assunto escolhido e a for- } \\
\text { mularem argumentos consistentes, que } \\
\text { possam sustentar sua tese. Em outras } \\
\text { palavras, precisam pesquisar para pla- } \\
\text { nejar a fala, tomando notas, inclusive, } \\
\text { em função da exigência do gênero; }\end{array}$ \\
\hline $\begin{array}{l}\text { Cada debatedor desempenha um pa- } \\
\text { pel definido, especialmente o primeiro } \\
\text { e o último de cada bancada, buscando } \\
\text { empregar a língua de maneira formal. }\end{array}$ \\
\hline $\begin{array}{l}\text { Os alunos têm a liberdade de empre- } \\
\text { gar a sua própria variedade linguís- } \\
\text { tica, adquirida no contexto familiar e } \\
\text { ao longo dos anos de escolarização. Pau- } \\
\text { latinamente, contudo, vão descobrindo } \\
\text { que há outras formas de falar mais } \\
\text { adequadas às situações formais; }\end{array}$ \\
\hline $\begin{array}{l}\text { O alunos que são favoráveis à moção pre- } \\
\text { cisam estar atentos ao que a bancada } \\
\text { opositora estará expondo (e vice-versa), } \\
\text { uma vez que será preciso ouvir os argu- } \\
\text { mentos contrários aos seus para compor } \\
\text { a contra-argumentação. Além disso, } \\
\text { ao longo do discurso de cada debatedor, } \\
\text { é possível que este seja interpelado pela } \\
\text { bancada oposta para lhe fazer perguntas, } \\
\text { o que reforça ainda mais a necessidade de } \\
\text { estar atento à fala do interlocutor; } \\
\text { Os alunos são ensinados a perceberem } \\
\text { que elementos como os gestos acompa- } \\
\text { nham o discurso e o reforçam. }\end{array}$ \\
\hline
\end{tabular}

Figura 1: O debate regrado como meio para atingir os objetivos traçados pelos PCN

Além do atendimento aos cinco objetivos mencionados, gostaríamos ainda de lembrar que outra vantagem de se trabalhar a oralidade por meio do gênero debate regrado é o fato de o aluno ser levado a posicionar-se frente a questões que se apresentam na vida em sociedade, uma vez que o pleno exercício da cidadania está atrelado à possibilidade de exposição do próprio ponto de vista e à convivência com posições ideológicas distintas. Nesse viés, destacamos um leque de possibilidades de trabalho com temas transversais, de modo a se realizar um trabalho integrado por várias áreas. Sobre esse assunto, os PCN (BRASIL, 1997, p. 40) reiteram que: "Por tratarem de questões sociais contemporâneas, que tocam profundamente o exercício de cidadania, os temas transversais oferecem 
inúmeras possibilidades para o uso vivo da palavra, permitindo muitas articulações com a área de Língua Portuguesa". o tema de cada debate norteará, por conseguinte, os diferentes conhecimentos que precisarão ser mobilizados e quais áreas de estudo serão tocadas quando os alunos assumirem a palavra.

Por fim, insistimos que é justamente a contribuição para a aquisição e o desenvolvimento da habilidade para falar em público em situações formais - capaz de dar voz aos alunos - o nosso princípio norteador. Quando lidamos com um corpo discente oriundo de classes sociais menos favorecidas e, por conseguinte, por tanto tempo silenciado, acreditamos que é nosso dever como educadores dar oportunidades para que esses alunos façam valer seus direitos por meio do uso público da fala. Exercitar a expressão oral formal significa, portanto, prover-lhes instrumentos para se posicionarem na sociedade.

A seguir, apresentamos uma amostra ${ }^{4}$ da primeira metade de um debate regrado cujo tema foi Liberdade de expressão e cuja moção foi Esta Casa acredita que a zoeira passou dos limites no Brasil. Conforme já expusemos, os alunos já sabiam qual seria o tema do debate, mas a moção (esse recorte mais específico) souberam apenas com quinze minutos de antecedência. Também, só no dia do debate, foi feito um sorteio para saber quais debatedores se colocariam a favor da moção e quais seriam contrários a ela.

O objetivo de tais "regras", conforme exposto na figura 1, é o de levar os alunos a pesquisarem sobre o assunto, numa ação interdisciplinar. Nesse sentido, há o incentivo para sempre estarem dispostos a considerar a multiplicidade de posicionamentos que pode envolver uma questão e, assim, se colocarem no lugar do outro para compreender o seu ponto de vista. Afinal, nesse modelo de debate, podem, por meio de sorteio, acabar fazendo parte de uma bancada que defende algo bem diferente do que pensam.

A seguir, os estudantes, chamados de L1 e L3, advogam a validade da moção, enquanto L2 e L4 discordam dela e tentam provar que é inadequada. Em outras palavras, a fim de convencer os juízes e a plateia, alternam-se discursos da defesa e de oposição. Para a transcrição das falas, optamos por não nos pautarmos pela língua escrita, justamente

4 Informamos que todos os procedimentos foram realizados em conformidade com as normas institucionais e que foram atendidas as exigências da Resolução $n^{0}$ 510, de 7 de abril de 2016, do Conselho Nacional de Saúde, referente a pesquisas envolvendo seres humanos. 
Sirley Ribeiro

Siqueira de

Oliveira

por ser outra modalidade linguística e ter características específicas, diferentes da modalidade oral. Preferimos seguir as normas que aparecem em Castilho \& Pretti (1986), as quais deixam em evidência os traços de planejamento on-line, típicos do discurso oral, como, por exemplo, hesitações, retomadas, falsas iniciações, etc.:

L1: as pessoas têm que acreditar que... que o que hoje é considerado como piada não tem caráter... tem caráter duvidoso... por quê? hoje em dia nada é levado a sério no Brasil... o que é uma coisa... uma situação preocupante... por exemplo o cenário político ele não é levado a sério... a... todos fazem piada com coisas que são muito importantes e que afetam diretamente na nossa vida... você simplesmente ri de um político fazendo sinal de arminha e dizendo [incompreensivel] pra todo mundo... não é engraçado não é uma piada mas no Brasil isto é considerado uma piada o que é muito sério... outra situação como hoje em dia humoristas podem falar tudo porque é considerado uma piada e é em nome do humor... mas o humor ele tem que ter limite... a oposição ela pode querer afirmar que isso é liberdade de expressão de cada um mas essa liberdade de expressão de cada um ela acaba quando fere a liberdade do outro... então não é...não eh::... é importante deixar claro como... nós somos todo dia afetados por esse tipo de piada que... simplesmente é uma:: são pessoas escondendo machismo... homofobia... intolerância religiosa... em forma de humor... e... isso tá completamente errado... eh:: as pessoas simplesmente disfarçam tudo no humor... as pessoas não entendem que existe um outro e que nem todo mundo vai rir do que você acha engraçado e as pessoas têm que pensar o que cada um acha engraçado porque a partir do momento que isso machuca uma outra pessoa... você não pode simplesmente rir disso e achar muito legal... pessoas... os jovens de hoje em dia eles tão cada vez entrando mais em depressão tendo ansiedade e isso é preocupante... as pessoas não percebem o quanto essas coisas estão interligadas (...)

É interessante observar que a estudante L1 tenta prever um possível argumento da bancada de oposição ao afirmar "a oposição ela pode querer afirmar que isso [a possibilidade de os humoristas fazerem piada com qualquer tema] é liberdade de expressão de cada um mas essa liberdade de expressão de cada um ela acaba quando fere a liberdade do outro". o intuito, obviamente, é o de desconstruir esse argumento antes mesmo 
de ser exposto, numa atitude de contra-argumentação prévia que se desenvolve ao serem expostas consequências negativas desse tipo de humor, como a depressão entre os jovens. Outro ponto a ser mencionado é o fato de que, embora tenha sida lembrada, antes de iniciar o debate, a primeira debatedora deveria definir os termos da moção de modo a delimitar, de maneira bastante clara, o andamento do debate, essa tarefa não foi cumprida, como veremos adiante na fala de L4.

A seguir, apresentamos a fala do segundo debatedor:

L2: Bom:: devo lembrar aos senhores que... devo lembrar aos senhores a questão da liberdade de expressão... como a minha querida deputada de defesa pontuou sobre a questão do humor como a liberdade de expressão... eu lembro sobre o humor... eh:: falar sobre coisas sérias... eu devo lembrar Oralidade formal e argumentação a você que o humor também pode ser uma forma de crítica ao sistema... porque nós temos diversas formas de questionar o sistema e o humor é uma delas porque é uma forma mais tangivel e mais acessivel a pessoas que não têm o conhecimento político:: um conhecimento geral muito grande sobre esse assunto e::: bom...eh:: devo lembrar a você também que a liberdade de expressão tem os seus princípios basicamente fincados no Iluminismo e na Revolução Francesa... Liberdade Igualdade e Fraternidade... bom... devo lembrar a você que:: eh::a liberdade de expressão tem que ser garantida por lei e bom... eh:: Esta Casa acredita que a zoeira passou dos limites... bom a zoeira como... vou falar grosso modo...

[o estudante 2 cedeu a palavra a outro colega debatedor que desejava lhe fazer uma pergunta]

Pergunta 1: o senhor citou os três pilares do Iluminismo Liberdade Igualdade e Fraternidade... mas você não acha que a zoeira está segregando e tirando a igualdade das pessoas?

L2: bom... nós devemos lembrar que... a igualdade é uma coisa relativa... a zoeira e o humor em nenhum momento vai segregar alguém em nenhum momento uma piada que nós iremos... que nós fazemos ou proferimos irá segregar algum tipo de pessoa ou simplesmente cercear a sua igualdade

[novamente o estudante cede a palavra a outro]

Pergunta 2: 0 senhor deputado tá dizendo que não... que em momento algum as pessoas segregam as outras com a zoeira sendo que isso ocorre bastante... as pessoas fazem piadas com::: esse tipo de coisa machismo homofobia racismo e [incompreensível]? 
Sirley Ribeiro

Siqueira de

Oliveira

L2: bom... isso vai de cada um... há pessoas que se magoam com esse tipo de piada e há pessoas que não se magoam com esse tipo de piada... então nós devemos respeitar a liberdade das pessoas de fazerem as suas piadas de fazerem as suas zoeiras... porque nós não podemos nós não sabemos qual será a reação da pessoa quanto a isso (...) devo lembrar a você também que piadas são formas de humor porque são formas de combate à depressão porque as pessoas riem as pessoas ficam felizes com piadas... com humor... (...)

L2, logo no início do seu discurso, retoma a fala da primeira debatedora: “(...) como a minha querida deputada de defesa pontuou sobre a questão do humor como a liberdade de expressão". A intenção é a de refutar os argumentos de L1 e desenvolver o seu discurso justamente pautando-se na liberdade de expressão, garantida a todos. Além disso, L2 também procura desconstruir a ideia exposta pela primeira debatedora acerca da relação entre piadas e depressão entre os jovens, ao afirmar: "piadas são formas de humor porque são formas de combate à depressão porque as pessoas riem as pessoas ficam felizes com piadas". Ainda dentro do tempo destinado à fala de L2, observamos que ele é interpelado por dois debatedores que fazem perguntas a ele, com o intuito de quebrar o fluxo do seu raciocínio. Nesse modelo de debate, não é necessário responder imediatamente às perguntas, como L2 fez. Uma alternativa possível seria a de completar a fala, concluindo o pensamento e, em seguida, responder as perguntas feitas.

Contrariamente ao ponto de vista de L2, o próximo estudante a argumentar, pertencente à bancada de defesa, também vai sustentar a ideia de que algumas piadas podem levar à depressão:

L3: a depressão que o deputado citou que:: as piadas[incompreensível] bom... dependendo de algumas piadas só alimentariam a depressão o bullying o ciberbullying esse tipo de coisa que pelo limite já ultrapassado da zoeira no Brasil é livre pra circular... assim como citando o caso do [cita o nome de um apresentador] onde ele fez piada com o poder público sem nenhum medo ou algum tipo de receio de que... sei lá... talvez ultrapassado o limite da zoeira... e isso afeta as pessoas psicologicamente... ou seja... não ajuda muito esse limite já ultrapassado... as pessoas... não ajuda... ou seja...o limite do... da zoeira no Brasil já passou... tanto que essa liberdade de expressão que você também citou 
ela acaba sendo quebrada porque às vezes a liberdade de expressão não é tão simples... ou seja... as pessoas aproveitam a liberdade de expressão para proliferar preconceito... estereótipos... esse tipo de coisa... e como:: mais pessoas começam a proliferar isso... os humores preconceituosos crescem... e ninguém entende como preconceito e sim como liberdade de expressão que é um [incompreensível] (...)

O discurso de L3 soma-se ao de L1, uma vez que ambos são da mesma bancada, a de defesa da moção Esta Casa acredita que a zoeira passou dos limites no Brasil. Nesse sentido, percebemos que é feita a reiteração do argumento de que algumas piadas promovem a depressão e que, em nome da liberdade de expressão, o preconceito tem sido reforçado e até banalizado: "as pessoas aproveitam a liberdade de expressão para Oralidade formal e argumentação proliferar preconceito...(...) e ninguém entende como preconceito e sim como liberdade de expressão.

A fala de L4, transcrita a seguir, proferida por uma estudante com um pouco mais de experiência em debates, se diferencia das demais porque L4 inicia seu discurso cumprimentando a todos os presentes, com o intuito de demonstrar cordialidade e respeito aos colegas. Consideramos bastante relevante esse aspecto, de modo que os alunos, quando recebem o feedback relativo à sua fala, são orientados a agirem assim e, nos próximos debates, a também incorporarem saudações aos demais debatedores, à plateia e aos juízes.

L4: boa tarde, eu me chamo L., sou integrante da Sociedade de Debates desse magnífico Colégio... eu saúdo a bancada de oposição... os juízes e essa plateia presente...e hoje vim me opor a essa moção... e antes de tudo... antes de começar a minha colocação... gostaria de questionar a bancada de defesa pela definição que não foi feita... porque em todo momento eles citam que a zoeira passou dos limites... mas o que seriam esses limites? Porque:: pra gente ponderar o que passou de um limite...a gente tem que ter bem claro... aonde é... aonde está esse limite... porque eu posso criticar como a deputada falou em seu primeiro discurso do... da defesa... eu posso:: zombar de um político que sinal de arminha como se isso fosse algo engraçado...mas na verdade eu posso estar levando isso pra um lado crítico...eu posso tá pensando... eh:: eu posso tá criticando o governo usando o humor como:: minha dupla já citou... como algo mais acessível... porque nem todo mundo...nem toda população ela 
Sirley Ribeiro

Siqueira de

Oliveira

vai ter o conhecimento pra fazer uma crítica política::...eh:: uma crítica séria... então eles utilizam do humor pra fazer esse tipo de crítica... $e$ esse exemplo que a senhora citou pode ser considerado... pode ser levado em consideração... então quando vocês dizem que a zoeira passou do limite... onde seria o limite? Isso teria passado do limite? Porque eh::: outro argumento trazido pela foi que como fere... como magoa alguém... é quando passou dos limites... isso seria... ahn... subentendido que passou dos limites... mas isso também é algo muito relativo... porque como foi também trazido pela minha bancada...é:: magoar é algo relativo...pessoas... tem pessoas que se magoam e tem pessoas que não se magoam... então por exemplo... um humorista que faz uma piada que... é levada prum lado que... essa piada magoa as pessoas... isso é uma generalização porque nem todo vai se magoar... então como que a gente vai fazer... vai proibir essa pessoa de falar... só porque ela tá magoando alguém? (...)

L4, da bancada oposta à moção, inicia seu discurso, com uma crítica à primeira debatedora da bancada de defesa, a qual, segundo o modelo de debate adotado, deveria ter cumprido o papel de definir a moção, isto é, delimitar ainda mais o objeto a ser debatido. Essa crítica, conforme já apontamos, fica evidente em "gostaria de questionar a bancada de defesa pela definição que não foi feita... porque em todo momento eles citam que a zoeira passou dos limites...mas o que seriam esses limites?" Novamente a experiência em debates que seguem esse modelo foi aproveitada pela debatedora L4 a fim apontar os deslizes da bancada de defesa, especialmente de L1. Essa experiência acumulada por L4 nos prova o quanto é importante um trabalho recorrente com a oralidade formal e que, se é verdade que só se aprende a escrever, escrevendo, também é comprovado que só se aprende a falar, falando.

\section{Considerações finais}

Esperamos ter respondido, ao longo desse trabalho, as questões enunciadas no início desse texto e sobre as quais nos debruçamos, a fim de mostrar o quanto é importante fazer da oralidade um objeto de ensino e como o gênero debate regrado pode ser alçado a instrumento para aprimorar a oralidade formal.

Além de todos os motivos já apontados, que justificam a importância de se trabalhar com a oralidade a partir do gênero debate regrado, lembramos, nestas palavras finais, que os alunos precisam ser orientados 
a manterem regras de cortesia e respeito, a fim de que a discussão sempre fique restrita ao campo das ideias. Se almejamos uma sociedade melhor, isso passa pela adoção de condutas condizentes com a civilidade.

Reiteramos, ainda, que é a partir da própria prática que são criadas e desenvolvidas as habilidades exigidas para a sustentação de ideias e, com o exercício constante, os educandos podem se tornar cada vez mais capazes de defenderem seus posicionamentos também na modalidade oral da língua. Desse modo, com esse entendimento de que se aprende a debater através da participação em debates e de que a modalidade oral da língua também deve ser um alvo da escola, é que reforçamos a importância de se oferecer cada vez mais oportunidades aos discentes de aprenderem através da experiência e, dessa maneira, paulatinamente, se tornarem mais confiantes e seguros ao assumirem a palavra em quaisquer contextos situacionais nos quais estiverem inseridos.

Nosso interesse é, portanto, pela formação de sujeitos cada vez mais autônomos, capazes de alçarem a sua voz em defesa de seus direitos a fim de que esses não sejam suprimidos ou concedidos em parte. Além disso, nosso propósito também é o de contribuir para ampliação do letramento de nossos alunos, de modo que sejam capazes de se expressar com desenvoltura também na modalidade oral, a qual, em situações formais, exigirá planejamento.

\section{REFERÊNCIAS}

BRASIL. MEC. Secretaria de Educação Fundamental. Parâmetros curriculares nacionais: Língua Portuguesa/ Secretaria de Educação Fundamental. - Brasília. 1997.

Base Nacional Curricular Comum. 3ª versão. Brasília: MEC, 2017.

CARVALHO, Robson Santos de \& FERRAREZI Jr., Celso. Oralidade na Educação Básica: o que saber, como ensinar. São Paulo: Parábola, 2018.

CASTILHO, Ataliba Teixeira de. \& PRETI, Dino. (orgs.). A linguagem falada culta na cidade de São Paulo: materiais para seu estudo. São Paulo: T. A. Queiroz, 1986. 
A língua falada no ensino de Português. São Paulo: Contexto, 1998

; BASILIO, Margarida. (org.) Gramática do Português falado. Campinas: Editora da UNICAMP/FAPESP, vol. IV, 1996.

COSTA-MACIEL, Débora Amorim Gomes da \& BILRO, Fabrini Katrine da Silva. O que é ensinar a oralidade? Análise das proposições didáti-

Sirley Ribeiro

Siqueira de

Oliveira cas apresentadas em livros destinados aos anos iniciais da Educação Básica. Educação em revista, Belo Horizonte, v.34, p. 1-29, 2018.

DOLZ, Joaquim, NOVERRAZ, Michèle e SCHNEUWLY, Bernard. Sequências didáticas para o oral e a escrita: apresentação de um procedimento. In: SCHNEUWLY, Bernard e DOLZ, Joaquim. Gênero orais e escritos na escola. Traduzido por Roxane Rojo e Glaís Sales Cordeiro. Campinas, SP: Mercado das Letras, 2004, p. 213-239.

GOMES-SANTOS, S.N. Modos de apropriação; do gênero debate regrado na escola: uma abordagem aplicada. DELTA, São Paulo, v. 25, p. 39-66, 2009.

KOCH, Ingedore Villaça. (org.) Gramática do Português falado. Campinas: Editora da UNICAMP/FAPESP, vol. vi, 1996.

Desvendando os segredos do texto. São Paulo: Cortez, 2002. \& ELIAS, Vanda Maria. Fala e escrita. In: : Ler e escrever: estratégias de produção textual. São Paulo: Contexto,2012.

LEAL, Telma Ferraz; GOIS, Sianne. (Orgs.) A oralidade na escola: a investigação do trabalho docente como foco de reflexão. Belo Horizonte: Autêntica, 2012.

MARCUSCHI, Luiz Antônio. Análise da conversação. São Paulo: Ática, 1986.

Da fala para a escrita: atividades de retextualização. São Paulo: Cortez, 2001. 
NEGREIROS, Gil \& VILAS BOAS, Gislaine. A oralidade na escola: um (longo) percurso a ser trilhado. Letras, Santa Maria, v.27, n.54, p. 115-126, jan./jun.2017.

NONATO, Sandoval. Processos de legitimação da linguagem oral no ensino de Língua Portuguesa: panorama histórico e desafios atuais. Cadernos Cedes. v. 38, n. 105, p. 222-239, Campinas, maio-ago.2018.

PERELMAN, Chain; OLBRECHTS-TYTECA, Lucie. Traité de Oralidade

l'argumentation. La Nouvelle Rhéthorique. Bruxelas: Éditions de l'Université de Bruxelles, 1958. formale argumentação 
